\title{
Latency and magnitude of the pupillary response during an imagery task
}

H. M. SIMPSON, FIONA M. MOLLOY, SHIRLEY M. IIALE, and M.H. CLIMAN. Carleton University. Ottawa, Canada

Pupillary reactions were continuously photographed while Ss attempted to generate images suggested by stimulus words. The nouns represented three levels of task difficulty in terms of the rated case with which the words evoke sensory images. Ss were required to press a key when an image occurred as well as subscquently describe the image. The results showed a significant increase in pupil size during the imagery task, but differential amounts of dilation were not exactly related to the three levels of task difficulty, whereas the time to maximum dilation was, suggesting that latency of dilation is a more sensitive index of difficulty in the imagery task.

A number of recent experiments have examined pupillary changes while Ss attempted to generate "mental images" suggested by stimulus words. Essentially three findings from this research have been emphasized. First, pupil size typically increases during the cognitive activity of generating images and the amount of dilation is related to the difficulty of the task. Thus, Paivio \& Simpson (1966) found that pupil size increased during an imagery task and dilation was greater to abstract than concrete words, a finding which is consistent with the hypothesis that imaging is more difficult in the case of abstract stimuli (e.g., Paivio, 1966). Similar results have been reported by others employing different cognitive tasks (e.g., Beatty \& Kahneman, 1966; Hess \& Polt, 1964). A second finding is that the response used by $S$ to indicate fulfillment of the task (e.g., a key press) contributes to the dilation effect, such that removing the response attenuates the pupillary change (e.g., Simpson \& Paivio, 1968). This finding is also consistent with other reports (e.g., Hakerem \& Sutton, 1966; Simpson, in press). For purposes of the present paper, the most important effect of removing the overt response is that, although a general dilation response remains during the imagery task, differential dilation to abstract and concrete stimuli disappears (e.g., Simpson \& Paivio, 1966). A third and more recent finding (Paivio \& Simpson, 1968) is that the latency of the pupillary response, that is, the time from the onset of the stimulus word to maximum pupil size is related to the difficulty of the task. In the experiment by Paivio \& Simpson (1968) no overt response was used and, accordingly, no significant difference was found in the amount of dilation to abstract and concrete stimuli. Latency of dilation was, however, related to word abstractness with pupil size reaching a maximum sooner in the case of concrete stimuli.

In view of these findings, the present experiment was designed to examine the relative sensitivity of both latency and magnitude of pupillary reactions as indices of the difficulty of an imagery task when an indication of task fulfillment is required of $S$. In addition, three levels of task difficulty (i.e., noun imagery) were used, since previous experiments had employed only two.

METHOD

Fifteen paid volunteer female university students, 17 to 25 years of age, served as Ss.

The stimulus items were 18 nouns selected by the Es from a pool of items which had been previously rated on a seven-point imagery (I) scale for the difficulty or ease with which the words evoke sensory images (Paivio, Yuille, \& Madigan. 1968). The stimulus items were selected to obtain words that were either high, medium, or low in rated I. The six high I words, which had a mean I rating of 6.60 were: bird. chair, child, clock, gueen, and sky. The six mediun 1 nouns (mean $I=4.07$ ) were: discovery, hope, product, science. shame, and silence. The six low I nouns (mean I $=2.79$ ) were: amount, event, knowledge. method, occasion, and position. Three basic sets of six words each were obtained from the 18 nouns by randomly assigning two words from each I category to each set. The items in each of these basic sets were arranged in two different random orders with the restriction that two words from the same I category did not occur in sequence within a list. The six lists were tape recorded, each word being separated by two signal tones. Thus, the sequence of taped stimuli was: word, tone 1 , tone 2 , word, tone 1 , tone 2 , and so on. The interval between the word and tone 1 as well as the interval between tone 1 and tone 2 was 15 sec. The interval between tone 2 and the next word varied from trial to trial between 15 and $20 \mathrm{sec}$.

The apparatus was similar to that described by Simpson \& Paivio (1968). Basically, it was a $1 \times 1 \times 8 \mathrm{ft}$ box with a goggle-like opening at one end which supported S's face while she looked into the box. The other and of the box contained an $11 \times 11 \frac{1}{2}$ in. rear projection screen. A target in the form of a $2 \times 2$ in. plus $(+)$ sign located in the center of the screen was used as a fixation point for S. Photographs of S's left eye were taken by a movie camera driven at a filming speed of two frames per sec. Stimuli were presented to $S$ auditorially.

The Ss were tested one at a time. All Ss received the same set of tape recorded instructions. Basically, $S$ was told to try to generate an image, that is, a mental picture of some object event, or situation that each word made her think about. The $S$ was told to press the button when she had generated an image, but to keep the image in her mind until she heard the first tone, which was her cue to begin a description of the mental image. The first tone was followed in $15 \mathrm{sec}$ by another tone, which was the signal for $\mathrm{S}$ to stop the verbal description, if it were not already complete, and relax mentally. The sequence of stimuli began with ir tone signalling a "relax" period. Thus, the sequence of conditions was: relax, image, description, relax, image, and so on.

The processed movie film was examined frame by frame on a film analyzer and the magnified pupil was measured in millimeters. Actual pupil size was computed by dividing the measured scores by the previously determined amount of magnification.

For each photographic frame, pupil size was averaged across $\mathrm{Ss}^{2}{ }^{2}$ separately for high, medium. and low I words during the "image" period, i.e., the time from presentation of a word until the first tone, and during the "control period (the time from the second tone until presentation of a word). The data for the entire image period as well as for the preceding $5 \mathrm{sec}$ of the control period are presented in Fig. 1. Inspection of the figure shows that pupil size during the control period was constant and similar for the three word types. Following presentation of either a high, medium, or low I word, there was a rapid dilation response and this increase in pupil size was maintained throughout the image period. The data are, therefore, entirely consistent with those of a previous experiment (Simpson \& Paivio, 1968), which used the same task conditions, i.e., a key press and verbal description, as the present study.

Magnitude of Dilation

Mean pupil size during the image period was significantly 


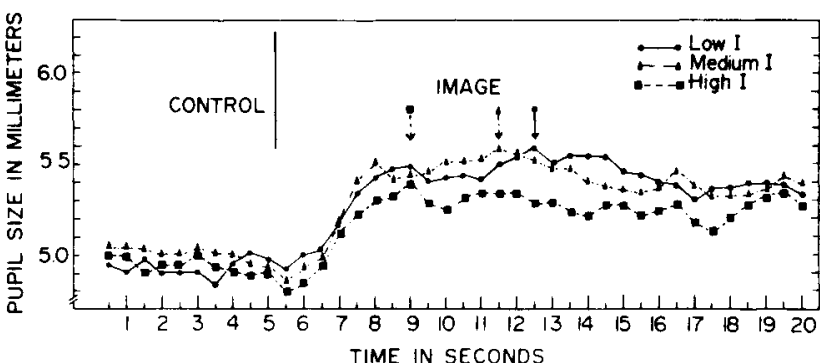

Fig. 1. Pupil size during attempts to generate images to high, medium, and low I words, and during a preceding control period. Arrows indicate points of maximal dilation.

larger than that in the control period for each of the three word types $(t=4.10, d f=14, p<.01 ; t=8.69, p<.001$ $t=10.16, p<.001$, for the high, medium, and low I words, respectively). This finding is consistent with previous reports (e.g., Paivio \& Simpson, 1966) that pupil size increases while S attempts to generate mental images. In addition, the amount of dilation during the image period differed among the word types. Pupil size during the image period was greater to low I than to high $I$ words $(t=2.43$, df $=14, p<.05)$, a finding which is in accord with other experiments (e.g., Simpson \& Paivio, 1968) as well as the hypothesis that it is more difficult to generate images to low I words (Paivio, 1966). Also consistent with the imagery hypothesis was the differential dilation to medium and high $I$ words $(t=2.79, \mathrm{df}=14$, $\mathrm{p}<.05$ ). There was, however, no difference in pupil size during imaging to the low and medium I words $(t=1.36$, $\mathrm{df}=14)$. Magnitude of dilation during the imagery task, therefore, only generally reflected task difficulty, since no difference was found in pupil size to low and medium I words. Latency of Dilation

The average time from presentation of a word until maximum pupil size during the image period was $4.13,6.02$, and $7.28 \mathrm{sec}$ for the high, medium, and low I words, respectively. The latencies are indicated to the nearest $1 / 2 \mathrm{sec}$ by the arrows in Fig. 1. Pupil size reached a maximum sooner to high I words than to low I words $(t=3.16, d f=14$, $\mathrm{p}<.01$ ); similar results have been reported previously (Paivio \& Simpson, 1966, 1968). The latency of dilation to the high I words was shorter than to the medium I words $(t=2.45$, $\mathrm{df}=14, \mathrm{p}<.05)$, a finding which is consistent with the imagery hypothesis as well as the data for magnitude of dilation reported above. In addition, pupil size reached a maximum sooner to the medium than to the low I words $(t=2.19, d f=14, p<.05)$, indicating that the data for the latency of dilation to the high, medium, and low I words were entirely consistent with the levels of task difficulty.

The results of the present study substantiate those of a previous experiment on the latency of pupillary dilation (Paivio \& Simpson, 1968) and indicate that at least with respect to the imagery task time to maximum pupil size is a more sensitive index of task difficulty than is pupil size itself.

\section{REFERENCES}

BEATTY, J., \& KAHNEMAN, D. Pupillary changes in two memory tasks. Psychonomic Science, 1966, 5, 371-372.

BERNICK, N., \& OBERLANDER, M. Effect of verbalization and two different modes of experiencing on pupil size. Presented at the Fifth Colloquium on the Pupil, University of Pennsylvania School of Medicine, Philadelphia, May, 1967.

HAKEREM, G., \& SUTTON, S. Pupillary response at visual threshold. Nature, 1966, 212, 485-586.

HESS, E. H., \& POLT, J. M. Pupil size in relation to mental activity during simple problem-solving. Science, 1964, 143, 1190-1192.

PAIVIO, A. Latency of verbal associations and imagery to noun stimuli as a function or abstractness and generality. Canadian Journal of Psychology, 1966, 20, 378-387.

PAIVIO, A., \& SIMPSON, H. M. The effect of word abstractness and pleasantness on pupil size during an imagery task. Psychonomic Science, 1966, 5, 55-56.

PAIVIO, A., \& SIMPSON, H. M. Magnitude and latency of the pupillary response during an imagery task as a function of stimulus abstractness and imagery ability. Psychonomic Science, 1968, 12, 45-46.

PAIVIO, A., YUILLE, J. C., \& MADIGAN, S. A. Concreteness, imagery, and meaningfulness values for 925 nouns. Journal of Experimental Psychology Monograph Supplement, 1968, 76, No. 1, Part 2.

SIMPSON, H. M. Effects of a task-relevant response on pupil size. Psychophysiology, in press.

SIMPSON, H. M., \& PAIVIO, A. Changes in pupil size during an imagery task without motor response involvement. Psychonomic Science, $1966,5,405-406$.

SIMPSON, H. M., \& PAIVIO, A. Effects on pupil size of manual and verbal indicators of cognitive task fulfillment. Perception \& Psychophysics, 1968, 3, 185-190.

NOTES

1. This research was supported by Grant APA-285 from the National Research Council of Canada to the first author.

2. Preliminary analyses indicated no differences in pupillary reaction to the various lists used and, accordingly, the data for high, medium, and low I words were collapsed across lists. 